\title{
Prevalence and Risk Factors of Nephrotoxicity Among Adult Cancer Patients at Mbarara Regional Referral Hospital
}

\author{
John Isiiko id ${ }^{\text {I-3 }}$ \\ Barnabas Atwiine ${ }^{4}$ \\ Joseph Oloro 5 \\ 'Department of Pharmacy, Mbarara \\ University of Science and Technology, \\ Mbarara, Uganda; ${ }^{2}$ Pharmacy \\ Biotechnology and Traditional Medicine \\ Center, Mbarara University of Science \\ and Technology, Mbarara, Uganda; \\ ${ }^{3}$ Department of Pharmacy, Uganda \\ Cancer Institute, Kampala, Uganda; \\ ${ }^{4}$ Department of Pediatrics and Child \\ Health, Mbarara University of Science \\ and Technology, Mbarara, Uganda; \\ ${ }^{5}$ Department of Pharmacology and \\ Therapeutics, Mbarara University of \\ Science and Technology, Mbarara, Uganda
}

Correspondence: John Isiiko Tel +25670444II00

Email isiikojohn@gmail.com
Background: Nephrotoxicity is common among cancer patients, yet some anti-cancer drugs, for example, platinum derivatives, are nephrotoxic and have narrow therapeutic indices. If nephrotoxicity is not managed, it can progress to kidney injury, which results in unregulated blood pressure, hormonal imbalance, electrolyte imbalance, body fluid imbalance and death. However, the burden of nephrotoxicity among adult cancer patients in Uganda is not documented in the literature.

Objective: This study assessed the prevalence and risk factors of nephrotoxicity among cancer patients receiving chemotherapy at Mbarara Regional Referral Hospital Cancer Unit (MRRHCU).

Methods: The study was a cross-sectional study carried out at the MRRHCU, Uganda. All the 206 adult cancer patients who received at least three cycles of chemotherapy and fulfilled the inclusion criteria were included. A data collection form was used to collect data, which was recorded into Microsoft Excel version 2013. Data were analyzed using Stata version 12.1.

Results: Of the 206 participants, 74 (35.9\%) developed nephrotoxicity with majority in stage $1(n=83,40.3 \%)$ and stage $2(n=55,26.7 \%)$. In the multivariate logistic regression of risk factors for nephrotoxicity, age $>50$ years old (aOR: $1.80,95 \%$ CI: $1.06,1.91 ; p>0.001$ ), hypertension (aOR: 1.71, 95\% CI: $1.74,1.94 ; p=0.011)$ and use of platinum agents (aOR: 2.04, 95\% CI: 1.82, 3.34; $p=0.002$ ) were significant independent risk factors of nephrotoxicity.

Conclusion: About one-third (1/3) of the adult cancer patients at MRRHCU develop nephrotoxicity, which indicates a high burden of nephrotoxicity. The prevention of progression of nephrotoxicity from grades 0,1 or 2 to grade 3 or 4 is therefore necessary, especially among the patients with risk factors, such as hypertension and age $>50$ years old and use of platinum agents.

Keywords: prevalence, risk factor, nephrotoxicity, cancer, Mbarara

\section{Introduction}

The burden of cancer is on the rise worldwide with about 19.3 million cases and 10 million cancer deaths in 2020, the majority of which occur in low- and middleincome countries. ${ }^{1}$ Chemotherapy remains one of the major options for the treatment of cancer. $^{2}$ Chemotherapy drugs are widely used either alone or in combination to treat various types of cancer, such as ovarian cancer, cervical cancer, testicular cancer, head and neck cancer, nasopharyngeal, and lung cancer. ${ }^{3}$ However, most chemotherapy drugs have narrow therapeutic indices; their therapeutic doses are close to their 
respective toxic doses. ${ }^{4}$ As such, chemotherapy drugs are associated with various risks of toxicities, which include nephrotoxicity, bone marrow suppression, gastrointestinal toxicity, ototoxicity and neuropathy. Of these, nephrotoxicity stands to be major and may largely contribute to restricted therapeutic use of some chemotherapy drugs. ${ }^{5,6}$

Nephrotoxicity is characterized by the decrease in glomerular filtration rate (GFR), which is clinically evaluated from increased serum creatinine ( $\mathrm{SCr}$ ) and decreased creatinine clearance $(\mathrm{CrCl})$ below $60 \mathrm{~mL} / \mathrm{min} / 1.73 \mathrm{~m}^{2} .7$ A study carried out in Poland found out that nephrotoxicity was a major clinical problem among cancer patients who received chemotherapy. ${ }^{8}$ Chemotherapy regimens containing platinum agents (cisplatin, carboplatin or oxaliplatin) have the most nephrotoxic effects. ${ }^{9,10}$ The major mechanism of nephrotoxicity is tubular necrosis, which leads to glomerular damage hence decreasing GFR. In Benin, the prevalence of nephrotoxicity was reported to be $16.1 \%{ }^{11}$ A study done in Indonesia showed a prevalence of nephrotoxicity of $34.1 \%$ among cancer patients who were treated with cisplatin. ${ }^{12}$

Despite preventive strategies, nephrotoxicity among cancer patients receiving chemotherapy, which includes hydration with normal saline, administration of mannitol and magnesium sulphate, still occurs. ${ }^{13}$ If nephrotoxicity is not managed, it can progress to kidney injury that results in unregulated blood pressure, hormonal imbalances, electrolyte imbalances and body fluid imbalance. ${ }^{8,14}$ This can impoverish the quality of life for cancer patients, increases their costs of hospitalization and may lead to death. ${ }^{15}$ Nevertheless, there has been inadequate reporting of ADR data, especially nephrotoxicity with the National Pharmacovigilance Centre, ${ }^{16}$ and no study has been done in Uganda to quantify the burden of nephrotoxicity among adult cancer patients. This constrains the development and implementation of strategies for the prevention and treatment of nephrotoxicity among adult cancer patients. ${ }^{13,17}$

Therefore, assessing the burden and risk factors of nephrotoxicity among adult cancer patients receiving chemotherapy is necessary for setting strategies to prevent permanent kidney damage, given the fact that approximately $90 \%$ of renal function might be lost before manifestation of clinical symptoms, such as swelling of the feet and ankles, nausea, vomiting, shortness of breath and fatigue. ${ }^{12}$

\section{Methods}

\section{Study Design and Setting}

The study was a retrospective cross-sectional study that involved a review of records for cancer patients from
July 2017 to May 2019 at MRRHCU. The MRRHCU had a bed capacity of 38 beds (20 and 18 beds for adult and pediatric patients respectively) with 2 specialist Oncologists, 1 Pharmacist and 7 Nurses.

\section{Study Participants}

All 206 adult cancer patients who received chemotherapy from June 2017 to May 2019 at MRRHCU, who fulfilled the inclusion criteria were included in the study.

\section{Inclusion Criteria}

The study included the records of adult cancer patients of either sex (18 years old and above), who fulfilled the following selection criteria.

- Patients who had confirmed cancer diagnosis.

- Patients who had available renal function test results.

- Patients who had normal baseline creatinine clearance of more than $90 \mathrm{~mL} / \mathrm{min} / 1.73 \mathrm{~m}^{2}$.

- Patients who had received at least three consecutive cycles of chemotherapy from June 2017 to May 2019.

\section{Exclusion Criteria}

- Patients with no confirmed cancer diagnosis

- Patients who had creatinine clearance of less than $90 \mathrm{~mL} / \mathrm{min} / 1.73 \mathrm{~m}^{2}$

- Patients with history of renal disease

\section{Data Collection}

A data collection checklist was developed based on the National Cancer Institute, common terminology criteria for adverse events (CTCAE) ${ }^{18}$ and it was used to extract data from the patient charts. The data collection checklist was structured to comprise four parts including sociodemographic data, medical information, drug information (Supplementary Table 1) and laboratory test results among the selected cancer patients.

The creatinine clearance was computed from the serum creatinine values using the Cockcroft-Gault formula. ${ }^{19}$

Two data collection assistants were trained, and the process of data collection was closely supervised by the principal investigator to ensure accuracy of data. In addition, a pretest was conducted on five percent of the sample size (10 patients) before the actual data collection for the study to provide feedback, which was used to improve the data collection tool. The results obtained from the pretest were not included in the final study results. The data collected was recorded in Microsoft Excel version 2013. 


\section{Data Analysis}

The data collected during the study was exported from Microsoft Excel version 2013 to Stata software version 12.1 for analysis. The measure of central tendency and proportions were the descriptive statistics used to describe the characteristics of the study population. The prevalence and severity of nephrotoxicity were analyzed using percentages and proportions by comparing the baseline eGFR with the eGFR after cycle 3 of chemotherapy basing on the CTCAE $^{18}$ (Supplementary Table 2). The association between the predictor variables and nephrotoxicity was measured using the Chi-square tests. Logistic regression was used to predict the risk factors for nephrotoxicity, where bivariate logistic regression was performed to determine the crude odds ratio (cOR) of nephrotoxicity with each predictor variable. All predictor variables with $\mathrm{p} \leq$ 0.25 were fit into a multivariate logistic regression analysis model to obtain the adjusted odds ratio (aOR) at 95\% level of confidence ${ }^{20}$ and control confounders. A value of $\mathrm{p}<$ 0.05 was considered statistically significant.

\section{Ethical Considerations}

The study was approved by the Mbarara University of Science and Technology Research Ethics Committee (MUST-REC) with approval reference number MUREC 1/7-2020. The study was also conducted in compliance with the declaration of Helsinki and confidentiality of the patients' information was protected. The participants' consent was waived by MUST-REC because the study was conducted retrospectively on patient files and had no direct interaction with them. All methods used in the study were in line with regulations and guidelines of MUST-REC and Mbarara Regional Referral Hospital Cancer Unit.

\section{Results}

\section{Participant Characteristics}

A total of 206 cancer patients who received at least three cycles of chemotherapy were included in the study. The mean age of the adult cancer patients was 49 years, the majority of whom were males $(52.4 \%)$. Of the adult cancer patients, 7 (3.4\%), 39 (18.9\%), 11 (5.3\%) and 53 (25.7\%) had diabetes mellitus, hypertension, obesity and HIV, respectively. Most of the cancer patients were married (67.9\%). The most prevalent cancers were breast cancer $18.5 \%(\mathrm{n}=$ 38 ) and Kaposi's sarcoma $13.1 \%(\mathrm{n}=27)($ Table 1$)$.
Table I Baseline Characteristics of Adult Cancer Patients at MRRHCU

\begin{tabular}{|l|l|l|}
\hline Characteristic & Category & Frequency (\%) \\
\hline Sex & Male & $108(52.4)$ \\
& Female & $98(47.6)$ \\
\hline Age category (years) & $18-50$ & $106(51.5)$ \\
& $>50$ & $100(48.5)$ \\
\hline Comorbidity & None & $107(51.9)$ \\
& DM & $7(3.4)$ \\
& Hypertension & $39(18.9)$ \\
& HIV & $53(25.7)$ \\
\hline Body mass index & Underweight & $44(21.4)$ \\
& Normal & $122(59.2)$ \\
& Over weight & $29(14.1)$ \\
& Obese & $11(5.3)$ \\
\hline Average BSA & Male & 1.69 \\
& Female & 1.57 \\
\hline Diagnosis & Breast cancer & $38(18.5)$ \\
& Kaposi' sarcoma & $27(13.1)$ \\
& Esophageal cancer & $25(12.1)$ \\
& Prostate cancer & $22(10.7)$ \\
& Stomach cancer & $79(9.2)$ \\
& Others & $75(36.4)$ \\
\hline Stage of cancer & Stage 2 & $19(9.2)$ \\
& Stage 3 & $42(20.4)$ \\
& Stage 4 & $56(27.2)$ \\
& Not staged & $89(43.2)$ \\
\hline
\end{tabular}

Abbreviation: BSA, body surface area.

\section{Prevalence of Nephrotoxicity}

The prevalence of nephrotoxicity among adult cancer patients at MRRHCU was 35.9\% $(n=74)$ (Figure 1).

\section{Severity of Nephrotoxicity}

Of the 206 adult cancer patients, majority had grade 1 nephrotoxicity $(\mathrm{n}=88,42.7 \%)$. Forty-nine $(23.8 \%)$, fiftynine $(28.6 \%)$ and ten $(4.9 \%)$ of the adult cancer patients had grade 0 , grade 2 and grade 3 nephrotoxicity respectively. Grade 4 was observed in none of the adult cancer patients (Figure 2).

\section{Risk Factors of Nephrotoxicity}

The $p$ values of the independent risk factors for nephrotoxicity in the bivariate model that were $<0.25$ include; age $>50$ years $(\mathrm{p}<0.001)$, hypertension $(\mathrm{p}=0.003)$, obesity $(\mathrm{p}=0.091)$ and platinum agents (0.001). These were considered for the multivariate logistic regression analysis (Table 2). 


\section{Prevalence of nephrotoxicity}

no nephrotoxicity $\quad$ Developed nephrotoxicity

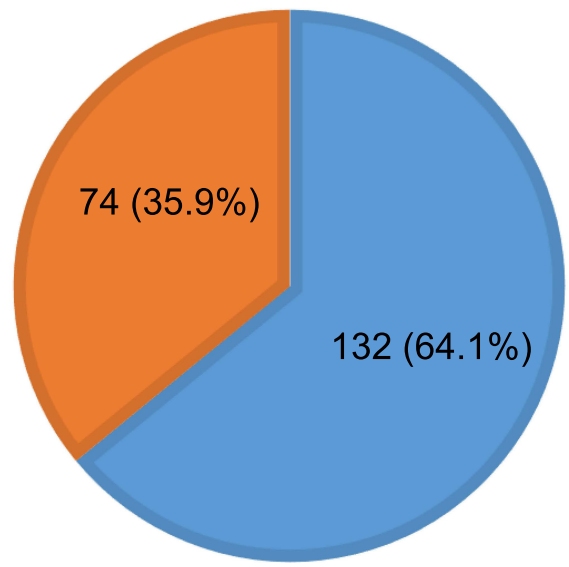

Figure I Prevalence of nephrotoxicity among adult cancer patients at MRRHCU.

The multivariate logistic regression showed that only age $>50$ years (aOR: $1.81,95 \%$ CI: $1.06,1.17$; $\mathrm{p}$ value $<0.001$ ), hypertension (aOR: 1.71, 95\% CI: 1.72, 1.98; $\mathrm{p}$ value $=$ 0.011 ) and platinum agents (aOR: 2.04, 95\% CI: 1.82 , 3.34; $p$ value $<0.002$ ) were the statistically significant risk factors of nephrotoxicity among adult cancer patients who received chemotherapy at MRRHCU (Table 3).

\section{Discussion}

The prevalence of nephrotoxicity among adult cancer patients at MRRHCU was $35.9 \%$. This shows a high burden of nephrotoxicity among the adult cancer patients at MRRHCU. The findings of this study are comparable to previous studies, for example, a study done in Indonesia about nephrotoxicity and associated risk factors among cancer patients documented a prevalence of $34.1 \%$. However, the current prevalence $(35.9 \%)$ is lower compared to the finding of a study in Japan $(48.8 \%){ }^{21}$ This difference may have resulted from the different methods used where the study included advanced esophageal cancer patients who received only one platinum drug regimen, whereas our study included patients of different types of cancer treated with various chemotherapy regimens. Similarly, a study in Kenya reported a relatively higher prevalence $(38.6 \%),{ }^{22}$ probably due to the difference in the technique used to determine nephrotoxicity, where a percentage increase in serum creatinine was used, rather than the estimated glomerular filtration rate in our study. In addition, the study employed a prospective study design unlike the retrospective study design used in our study. A related study that investigated the prevalence of chronic kidney disease in south-western Uganda reported a decline in kidney function in $15.4 \%$ of the general medical patients who were admitted to the medical ward of MRRH. ${ }^{23}$

The most prevalent grade of nephrotoxicity was grade 1 followed by grade 2 . This is comparable with the findings of a study, which was done in the Netherlands that reported $25 \%$ for grade 2 and $8.0 \%$ for grade 3 nephrotoxicity, respectively. ${ }^{24}$ Even though the proportion of

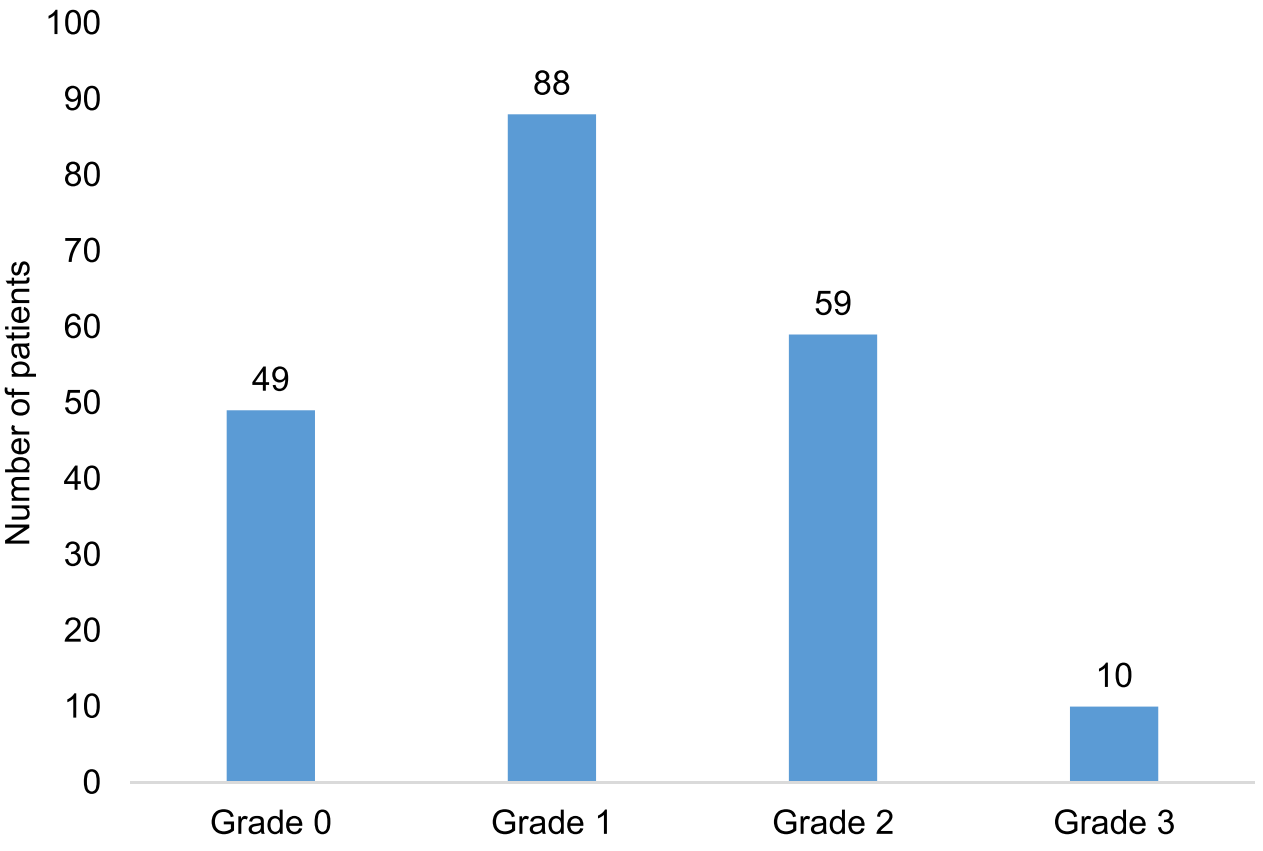

Figure 2 Grades of nephrotoxicity of adult cancer patients at MRRHCU. 
Table 2 Bivariate Logistic Regression Analysis of the Independent Risk Factors for Nephrotoxicity Among Adult Cancer Patients at MRRHCU

\begin{tabular}{|c|c|c|c|c|c|c|c|}
\hline \multirow[t]{2}{*}{ Characteristic Variable } & \multirow{2}{*}{\multicolumn{2}{|c|}{ Level }} & \multicolumn{2}{|c|}{ Presence of Nephrotoxicity } & \multirow[t]{2}{*}{ COR } & \multirow[t]{2}{*}{$P$ value } & \multirow[t]{2}{*}{$95 \% \mathrm{Cl}$} \\
\hline & & & Yes $(n=74)$ & No $(n=132)$ & & & \\
\hline \multirow[t]{2}{*}{ Age } & \multirow{2}{*}{\multicolumn{2}{|c|}{$\begin{array}{l}18-50 \\
>50\end{array}$}} & 20 & 86 & Ref & & \\
\hline & & & 54 & 46 & 1.08 & 0.000 & $1.06-1.11$ \\
\hline \multirow[t]{2}{*}{ Sex } & \multirow{2}{*}{\multicolumn{2}{|c|}{$\begin{array}{l}\text { Male } \\
\text { Female }\end{array}$}} & 40 & 67 & Ref & & \\
\hline & & & 34 & 65 & 1.14 & 0.650 & $0.65-2.02$ \\
\hline \multirow[t]{2}{*}{ Hypertension } & \multirow{2}{*}{\multicolumn{2}{|c|}{$\begin{array}{l}\text { No } \\
\text { Yes }\end{array}$}} & 50 & 113 & Ref & & \\
\hline & & & 24 & 19 & 2.86 & 0.003 & $1.44-5.68$ \\
\hline HIV & \multirow{2}{*}{\multicolumn{2}{|c|}{$\begin{array}{l}\text { Negative } \\
\text { Positive }\end{array}$}} & 57 & 96 & Ref & & \\
\hline & & & 17 & 36 & 0.80 & 0.499 & $0.4 I-I .54$ \\
\hline Diabetes mellitus & \multirow{2}{*}{\multicolumn{2}{|c|}{$\begin{array}{l}\text { No } \\
\text { Yes }\end{array}$}} & 71 & 128 & Ref & & \\
\hline & & & 3 & 4 & 1.35 & 0.698 & $0.29-6.21$ \\
\hline Obesity & \multirow{2}{*}{\multicolumn{2}{|c|}{$\begin{array}{l}\text { No } \\
\text { Yes }\end{array}$}} & 73 & 122 & Ref & & \\
\hline & & & 1 & 10 & 0.17 & 0.091 & $0.02-1.33$ \\
\hline \multirow[t]{16}{*}{ Chemotherapy Drugs } & \multirow[t]{2}{*}{ Platinum agents } & No & 42 & 101 & Ref & & \\
\hline & & Yes & 32 & 31 & 3.64 & 0.001 & $2.32-5.94$ \\
\hline & \multirow[t]{2}{*}{ Alkylating agents } & No & 62 & 65 & Ref & & \\
\hline & & Yes & 12 & 67 & 1.64 & 0.65 & $0.27-4.65$ \\
\hline & \multirow[t]{2}{*}{ Antimetabolites } & No & 17 & 84 & Ref & & \\
\hline & & Yes & 09 & 48 & 0.96 & 1.12 & $0.5 \mathrm{I}-3.93$ \\
\hline & \multirow[t]{2}{*}{ Vinca alkaloids } & No & 63 & 46 & Ref & & \\
\hline & & Yes & II & 86 & 1.33 & 0.89 & $0.88-4.91$ \\
\hline & \multirow[t]{2}{*}{ Taxanes } & No & 71 & 101 & Ref & & \\
\hline & & Yes & 03 & 31 & 0.72 & 1.98 & $0.39-5.14$ \\
\hline & \multirow[t]{2}{*}{ Anthracyclines } & No & 64 & 53 & Ref & & \\
\hline & & Yes & 10 & 79 & 2.12 & 2.01 & $0.87-3.92$ \\
\hline & \multirow[t]{2}{*}{ Cortico-steroids } & No & 51 & 30 & Ref & & \\
\hline & & Yes & 23 & 102 & 1.35 & 1.77 & $0.53-4.73$ \\
\hline & \multirow[t]{2}{*}{ Other treatments } & No & 66 & 51 & Ref & & \\
\hline & & Yes & 08 & 81 & 0.91 & 1.88 & $0.97-2.41$ \\
\hline
\end{tabular}

Note: Bold: Statistically significant.

Abbreviations: cOR, crude odds ratio; Ref, reference groups.

cancer patients with grade 3 nephrotoxicity is small $(<10.0 \%)$, it should be given attention because it can easily progress to total kidney damage. ${ }^{25}$ Therefore, grading of nephrotoxicity is important as it signals a need for drugdose adjustments or discontinuation of chemotherapy until the normal kidney function is restored among adult cancer patients treated with chemotherapy. ${ }^{13,26}$

The results from the bivariate logistic regression analysis showed that the $\mathrm{p}$-values for the risk factors; age $>50$ years old $(p<0.001)$, hypertension $(p=0.003)$, obesity $(p=0.091)$ and platinum agents $(p=0.04)$ were less than 0.2 hence selected for the multivariate logistic regression analysis. ${ }^{20}$

In the multivariate logistic regression analysis, having an age of $>50$ years, hypertension and use of platinum agents were statistically significant ( $\mathrm{p}<0.05$ ).

The aOR for age above 50 years was 1.81 , implying that adult cancer patients aged $>50$ years are 1.81 times as likely to develop nephrotoxicity as those aged 50 years and below. This is consistent with previous studies conducted in China, which reported that nephrotoxicity was higher in the elderly 
Table 3 Multivariate Logistic Regression Analysis of the Risk Factors for Nephrotoxicity Among Adult Cancer Patients at MRRHCU

\begin{tabular}{|c|c|c|c|c|c|c|}
\hline \multirow[t]{2}{*}{ Variable } & \multirow[t]{2}{*}{ Level } & \multicolumn{2}{|c|}{ Nephrotoxicity } & \multirow[t]{2}{*}{ aOR } & \multirow[t]{2}{*}{$P$ value } & \multirow[t]{2}{*}{$95 \% \mathrm{Cl}$} \\
\hline & & Yes $(n=74)$ & No $(n=132)$ & & & \\
\hline \multirow[t]{2}{*}{ Age } & $18-50$ & 20 & 86 & Ref & & \\
\hline & $>50$ & 54 & 46 & 1.81 & 0.000 & $1.06-1.97$ \\
\hline \multirow[t]{2}{*}{ Hypertension } & No & 50 & 113 & Ref & & \\
\hline & Yes & 24 & 19 & I.7I & 0.011 & $1.72-1.98$ \\
\hline \multirow[t]{2}{*}{ Obesity } & No & 73 & 122 & Ref & & \\
\hline & Yes & 1 & 10 & 0.13 & 0.646 & $0.01-2.15$ \\
\hline \multirow[t]{2}{*}{ Platinum agents } & No & 45 & 103 & Ref & & \\
\hline & Yes & 29 & 29 & 2.04 & 0.002 & $1.82-3.34$ \\
\hline
\end{tabular}

Note: Bolded figures indicate statistically significant associations.

Abbreviation: aOR, adjusted odds ratio.

cancer patients than in patients who were below 50 years old. $^{27,28}$ The increase in age is associated with structural and functional renal changes and the changes in kidney function with normal aging are the most dramatic of any human organ or organ system. ${ }^{29}$ A meta-analysis study of medicationinduced nephrotoxicity in older patients reported that older patients are exposed to potential nephrotoxic drugs or polypharmacy, which may lead to a decline in kidney function hence a risk for developing nephrotoxicity. ${ }^{30}$ This is in line with our study findings, where about three in four adult cancer patients who developed nephrotoxicity were above the age of 50 years.

Among the risk factors identified for nephrotoxicity in our study was hypertension; adult cancer patients who had hypertension were 1.7 times more likely to develop nephrotoxicity as compared to the non-hypertensive patients. The results of our study are similar to the findings of the previous studies done in the United States of America, ${ }^{10}$ Switzerland, ${ }^{31}$ China $^{32}$ and Brazil, ${ }^{33}$ that reported hypertension as a significant risk factor for developing nephrotoxicity among adult cancer patients treated with chemotherapy. Another related study done in south-western Uganda reported hypertension to be a significant risk factor for the decline in renal function among patients admitted to the medical ward of MRRH. ${ }^{23}$ Uncontrolled hypertension leads to high intra-glomerular pressure, which damages the blood vessels in the kidney, thus damaging glomeruli and resulting in reduced GFR. ${ }^{34}$

Our study revealed that adult cancer patients who received platinum agents were two times likely to develop nephrotoxicity than those who received other treatment regimens, a finding similar to other studies done in Switzerland, ${ }^{31}$
Canada, ${ }^{35}$ Brazil, $^{36}$ and Ethiopia. ${ }^{37}$ The high prevalence of nephrotoxicity among adult cancer patients who received platinum agents may be due to the preventive strategies used where hydration with normal saline and administration of magnesium sulphate were the preventive measures for nephrotoxicity. Other strategies such as administration of mannitol should be considered while developing a pharmaceutical care plan for such patients. ${ }^{13}$

A major mechanism of platinum-induced nephrotoxicity is tubular necrosis, which results in glomerular damage leading to a decrease in GFR. Other mechanisms are decreased urinal drainage, which causes an increase in intra-tubular pressure and vasoconstriction of the efferent artery. $^{38,39}$

The strength of the study included a relatively high number of participants. Nevertheless, the study was limited by the retrospective study design where we relied on recorded data in the patient files and any missing information could not be obtained. The study was also done in a single centre.

\section{Conclusion}

Over a third of the adult cancer patients develop nephrotoxicity during the course of their treatment with chemotherapy at Mbarara Regional Referral Hospital Cancer Unit. The majority of patients with nephrotoxicity had grade 1 and grade 2 . Age of $>50$ years old and hypertension were independent risk factors of nephrotoxicity.

Early screening for nephrotoxicity at MRRHCU and in other regional cancer centers should be considered to strengthen the strategies for the preventive measures of nephrotoxicity among cancer patients that receive 
chemotherapy. The diagnostics for nephrotoxicity should be improved in order to allow for appropriate screening, preferably on-site laboratory investigations should be introduced.

Preventive measures for nephrotoxicity should be ensured in order to avoid minimizing the risk of nephrotoxicity.

\section{Abbreviations}

AKI, Acute Kidney Injury; aOR, Adjusted Odds Ratio; BMI, Body Mass Index; BSA, Body Surface Area; CI, Confidence Interval; cOR, Crude Odds Ratio; $\mathrm{CrCl}$, Creatinine Clearance; CTCAE, Common Terminology Criteria for Adverse Events; eGFR, Estimated Glomerular Filtration Rate; GFR, Glomerular Filtration Rate; MRRH, Mbarara Regional Referral Hospital; MRRHCU, Mbarara Regional Referral Hospital Cancer Unit; MUST, Mbarara University of Science and Technology; MUST-REC, Mbarara University of Science and Technology Research Ethics Committee; SCr, Serum Creatinine; WHO, World Health Organization.

\section{Data Sharing Statement}

All the data in support of the conclusions of this article are included within this manuscript.

\section{Ethical Approval}

Ethical approval of the study was obtained from the Research Ethics Committee at Mbarara University of Science and Technology as the Institutional review board for authorization to conduct the research (MUREC 1/ 7-2020). All methods used in the study were in line with regulations and guidelines of the Research Ethics Committee and Mbarara Regional Referral Hospital Cancer Unit.

\section{Consent for Publication}

All authors of this manuscript agreed to its submission and publication.

\section{Acknowledgments}

The authors applause the study participants, data collection assistants and health workers at the cancer unit of Mbarara Regional Referral Hospital for their good cooperation throughout the study period.

\section{Author Contributions}

All authors made a significant contribution to the work reported whether that is in the conception, study design, execution, acquisition of data, analysis and interpretation, or in all these areas; took part in drafting, revising or critically reviewing the article; gave final approval of the version to be published; have agreed on the journal to which the article has been submitted; and agree to be accountable for all aspects of the work.

\section{Funding}

This study was funded by PHARMBIOTRAC a project under the funding of World Bank at Mbarara University of Science and Technology.

\section{Disclosure}

The authors hereby declare that they have no conflicts of interest in this work.

\section{References}

1. GLOBOCAN. New global cancer data; 2020. Available from: https:// www.uicc.org/news/globocan-2020-new-global-cancer-data. Accessed May 30, 2021.

2. Miller KD, Siegel RL, Lin CC, et al. Cancer treatment and survivorship statistics, 2016. CA Cancer J Clin. 2016;66(4):271-289.

3. Horie S, Oya M, Nangaku M, et al. Guidelines for treatment of renal injury during cancer chemotherapy 2016. Clin Exp Nephrol. 2018;22 (1):210-244. doi:10.1007/s10157-017-1448-z

4. Krens SD, Lassche G, Jansman FGA, et al. Dose recommendations for anticancer drugs in patients with renal or hepatic impairment. Lancet Oncol. 2019;20(4):e200-e207. doi:10.1016/S1470-2045(19) 30145-7

5. Mieczkowski M, Matuszkiewicz-Rowińska J, Kościelska M. [Anticancer agents nephrotoxicity]. Wiadomosci Lekarskie. 2015;68(4 Pt 2):650-654. Polish.

6. Vaseghi G, Abed A, Jafari E, Eslami N, Eshraghi A. Assessment of adverse drug reaction due to cancer chemotherapy in a teaching oncology hospital in Isfahan, Central of Iran. Rev Recent Clin Trials. 2016;11(3):266-272. doi:10.2174/157488711066615081 8112648

7. Marvin JL, Levine BJ, Papas M, Rosini JM. An evaluation of the incidence of nephrotoxicity after a loading dose of vancomycin in patients with severe renal impairment. J Emerg Med. 2019;56 (6):701-708. doi:10.1016/j.jemermed.2019.03.020

8. Małyszko J, Kozłowska K, Kozłowski L, Małyszko J. Nephrotoxicity of anticancer treatment. Nephrol Dialys Transplant. 2016;32 (6):924-936.

9. Rébé C, Demontoux L, Pilot T, Ghiringhelli F. Platinum derivatives effects on anticancer immune response. Biomolecules. 2019;10(1):13. doi:10.3390/biom 10010013

10. Faig J, Haughton M, Taylor RC, et al. Retrospective analysis of cisplatin nephrotoxicity in patients with head and neck cancer receiving outpatient treatment with concurrent high-dose cisplatin and radiotherapy. Am J Clin Oncol. 2018;41(5):432-440. doi:10.1097/ COC.0000000000000301

11. Gbaguidi GN, Houehanou CY, Amidou SA, Vigan J, Houinato DS, Lacroix P. Prevalence of abnormal kidney function in a rural population of Benin and associated risk factors. BMC Nephrol. 2021;22 (1):116. doi:10.1186/s12882-021-02316-y

12. Prasaja Y, Sutandyo N, Andrajati R. Incidence of cisplatin-induced nephrotoxicity and associated factors among cancer patients in Indonesia. APJCP. 2015;16(3):1117-1122. doi:10.7314/APJCP.2015. 16.3.1117 
13. Crona DJ, Faso A, Nishijima TF, McGraw KA, Galsky MD, Milowsky MI. A systematic review of strategies to prevent cisplatin-induced nephrotoxicity. Oncologist. 2017;22(5):609-619. doi:10.1634/theoncologist.2016-0319

14. Lameire N, Kruse V, Rottey S. Nephrotoxicity of anticancer drugs-an underestimated problem? Acta Clin Belg. 2011;66(5):337-345.

15. Silver SA, Chertow GM. The economic consequences of acute kidney injury. Nephron. 2017;137(4):297-301. doi:10.1159/000475607

16. Ndagije H, Nambasa V, Namagala E, et al. Targeted spontaneous reporting of suspected renal toxicity in patients undergoing highly active anti-retroviral therapy in two public health facilities in Uganda. Drug Safety. 2015;38(4):395-408. doi:10.1007/s40264-015-0277-9

17. Wu H, Huang J. Drug-induced nephrotoxicity: pathogenic mechanisms, biomarkers and prevention strategies. Curr Drug Metab. 2018;19(7):559-567. doi:10.2174/1389200218666171108154419

18. National Cancer Institute. Common Terminology Criteria for Adverse Events (CTCAE); 2017. Available from: https://ctep.cancer.gov/pro tocoldevelopment/electronic_applications/ctc.htm\#ctc_50. Accessed May 30, 2021.

19. Shahbaz H, Gupta M. Creatinine clearance. In: StatPearls. Treasure Island (FL): StatPearls Publishing Copyright (C) 2021, StatPearls Publishing LLC; 2021.

20. Variyath AM, Brobbey A, Chen F. Variable selection in multivariate multiple regression. PLoS One. 2020;15(7):e0236067. doi:10.1371/ journal.pone.0236067

21. Mohri J, Katada C, Ueda M, et al. Predisposing factors for chemotherapy-induced nephrotoxicity in patients with advanced esophageal cancer who received combination chemotherapy with docetaxel, cisplatin, and 5-fluorouracil. J Transl Intern Med. 2018;6 (1):32-37. doi:10.2478/jtim-2018-0007

22. Mwenda V, Githuku J, Gathecha G, Wambugu BM, Roka ZG, Ong'or WO. Prevalence and factors associated with chronic kidney disease among medical inpatients at the Kenyatta National Hospital, Kenya, 2018: a cross-sectional study. Pan Afr Med J. 2019;33:321. doi:10.11604/pamj.2019.33.321.18114

23. Kalima N, Gabriel B, Muhindo R, Muyingo A. Chronic kidney disease in patients admitted to the medical ward of Mbarara Regional Referral Hospital in southwestern Uganda: prevalence and associated factors. Int J Med Biomed Res. 2015;4:107-116.

24. Hoek J, Bloemendal KM, van der Velden LA, et al. Nephrotoxicity as a dose-limiting factor in a high-dose cisplatin-based chemoradiotherapy regimen for head and neck carcinomas. Cancers. 2016;8(2):21. doi:10.3390/cancers8020021

25. Tanaka M, Horinouchi H. Reduction in nephrotoxicities using short hydration for chemotherapy containing cisplatin: a consecutive analysis of 467 patients with thoracic malignancies. ESMO Open. 2018;3 (4):e000342.
26. Zhang QY, Wang FX, Jia KK, Kong LD. Natural product interventions for chemotherapy and radiotherapy-induced side effects. Front Pharmacol. 2018;9:1253. doi:10.3389/fphar.2018.01253

27. Wen J, Zeng M, Shu Y, et al. Aging increases the susceptibility of cisplatin-induced nephrotoxicity. Age (Dordrecht, Netherlands). 2015;37(6):112. doi:10.1007/s11357-015-9844-3

28. Duan Z, Cai G, Li J, Chen X. Cisplatin-induced renal toxicity in elderly people. Ther Adv Med Oncol. 2020;12:1758835920923430. doi:10.1177/1758835920923430

29. Wang X, Bonventre JV, Parrish AR. The aging kidney: increased susceptibility to nephrotoxicity. Int $J$ Mol Sci. 2014;15 (9):15358-15376. doi:10.3390/ijms 150915358

30. Fusco S, Garasto S, Corsonello A, et al. Medication-induced nephrotoxicity in older patients. Curr Drug Metab. 2016;17(6):608-625. doi:10.2174/1389200217666160406115959

31. Galfetti E, Cerutti A, Ghielmini M, Zucca E, Wannesson L. Risk factors for renal toxicity after inpatient cisplatin administration. $B M C$ Pharmacol Toxicol. 2020;21(1):19. doi:10.1186/s40360-020-0398-3

32. Hsu CN, Lee CT, Su CH, et al. Incidence, outcomes, and risk factors of community-acquired and hospital-acquired acute kidney injury: a retrospective cohort study. Medicine. 2016;95(19):e3674. doi:10.1097/MD.0000000000003674

33. Santos MLC, de Brito BB, da Silva FAF, Botelho A, de Melo FF. Nephrotoxicity in cancer treatment: an overview. World J Clin Oncol. 2020;11(4):190-204. doi:10.5306/wjco.v11.i4.190

34. Souza VB, Silva EN, Ribeiro ML, Martins Wde A. Hypertension in patients with cancer. Arq Bras Cardiol. 2015;104(3):246-252.

35. Wertman JN, Melong N. The identification of dual protective agents against cisplatin-induced oto- and nephrotoxicity using the zebrafish model. Elife. 2020;9:e56235.

36. Vasconcellos VF, Marta GN, Da silva EM, Gois AF, de Castria TB, Riera R. Cisplatin versus carboplatin in combination with third-generation drugs for advanced non-small cell lung cancer. Cochrane Database Syst Rev. 2020;1(1):Cd009256.

37. Workalemahu G, Abdela OA. Chemotherapy-related adverse drug reaction and associated factors among hospitalized paediatric cancer patients at hospitals in North-West Ethiopia. Drug Healthc Patient Saf. 2020;12:195-205.

38. Barnett LMA, Cummings BS. Nephrotoxicity and renal pathophysiology: a contemporary perspective. Toxicol Sci. 2018;164 (2):379-390. doi:10.1093/toxsci/kfy159

39. McSweeney KR, Gadanec LK. Mechanisms of cisplatin-induced acute kidney injury: pathological mechanisms, pharmacological interventions, and genetic mitigations. Cancers. 2021;13(7):1572.

\section{Publish your work in this journal}

Cancer Management and Research is an international, peer-reviewed open access journal focusing on cancer research and the optimal use of preventative and integrated treatment interventions to achieve improved outcomes, enhanced survival and quality of life for the cancer patient.
The manuscript management system is completely online and includes a very quick and fair peer-review system, which is all easy to use. Visit http://www.dovepress.com/testimonials.php to read real quotes from published authors. 